\title{
ANGIOLYMPHOID HYPERPLASIA WITH EOSINOPHILIA - A CASE REPORT
}

\author{
Wg Cdr YM SIRPAL
}

MJAFI 2002; 58 : 154-155

KEY WORD :Angiolymphoid hyperplasia with eosinophilia.

\section{Introduction}

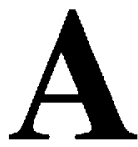

ngiolymphoid hyperplasia with eosinophilia (ALHE), also known as epithelioid haemangioma $[1,2]$ or histiocytoid haemangioma, is currently considered to be a true neoplasm rather than a reactive phenomenon [3]. This entity is uncommon and has been frequently confused with Kimura's disease in the past $[1,2]$. One such case encountered recently is presented.

\section{Case Report}

A 29 year old male presented with multiple, dome-shaped. flesh coloured nodules which were getting superficially ulcerated and crusted owing to pruritis of approximately 2 years duration. The lesions were located over concha and external auditory meatus of right ear. The largest single nodule measured $2 \mathrm{cms}$ in diameter. There was no localized lymphadenopathy and peripheral eosinophilia. He was clinically treated as a case of tubercular verrucosa cutis and was administered anti-tubercular therapy for six months without any significant remission of the disease.

Excision biopsy of a nodule done later, revealed a reasonably circumscribed intra-dermal mass composed of numerous, variablesized, proliferating blood vessels (capillaries and medium sized arteries), lined by plump epithelioid endothelial cells; giving a hobnail or tombstone appearance; variable number of eosinophils (in different tissue sections); and diffuse, dense collections of lymphocytes around vessels (Fig 1\&2). No lymphoid follicles were noted in the lesion. A diagnosis of ALHE was made.

\section{Discussion}

Mehregan and Shapira [4] described ALHE in young adults developing solitary or more commonly multiple nodules located intradermally or subcutaneously or both, on the head, around the ear or the hairline. It may also involve the oral mucosa [5]. It affects middle aged adults of either sex. Earlier, ALHE was considered synonymous with Kimura's disease [4] from which it has now been differentiated. Kimura's disease is often associated with localized lymphadenopathy with eosinophilia, and is usually more deeply located, shows tendency to more fibrosis and has far less vascular proliferation. Epithelioid endothelium is not a feature in Kimura's disease $[1,3,6]$. ALHE can be distinguished from angiosarcoma since the latter occurs in older age group and lesions comprise freely anastomosing sinusoidal vessels lined by mitotically active endothelial cells [3].

Spontaneous regression is seen in majority of cases

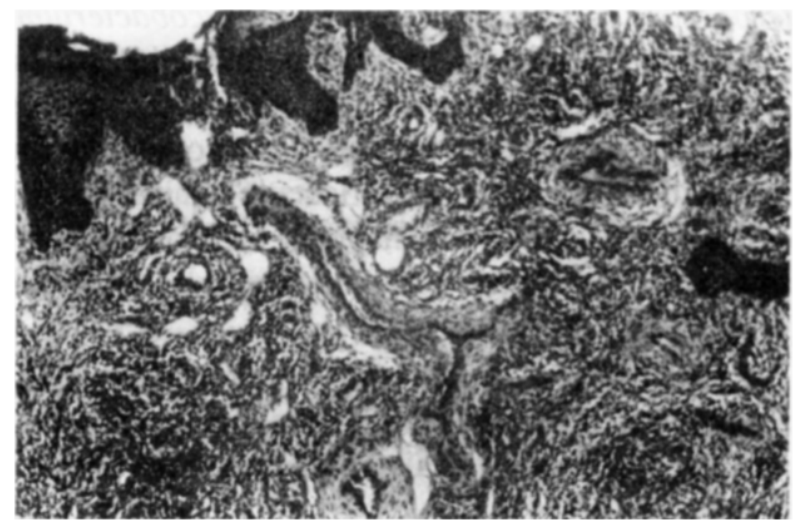

Fig. 1: Tumour comprising large number of blood vessels with collection of lymphocytes and eosinophils underneath epidermis $(\mathrm{H} \& \mathrm{E} \times 60)$

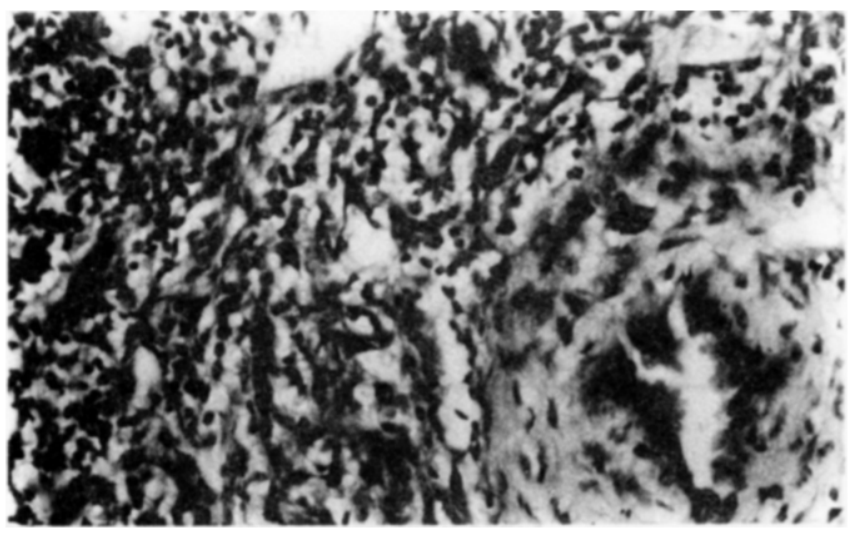

Fig. 2: Higher magnification of Fig. I showing blond vessel lined by plump endothelial cells having large vesicular nuclei and the cellular infiltrate of lymphoxytes and eosinophils in stroma ( $\mathrm{H} \& \mathrm{E} \times 200)$ 
after a variable period of time ranging from 3-6 months. Intralesional corticosteroids, laser and radiotherapy have been used in some cases with benefit [7].

\section{References}

1. Urabe A. Tsuneyoshi M. Enjoji M. Epithelioid haemangioma versus Kimura's disease:a comparative clinico pathologic study. Am J Surg Pathol 1987;11:758-66.

2. Chan JKC, Hui PK, Ng CS, Yuen NWF, Kung ITM, Gwi E. Epithelioid haemangioma (angiolymphoid hyperplasia with eosinophilia) and Kimura's disease in Chinese. Histopathology 1989;15:557-74.

3. Flatcher CDM. Selected summaries : soft tissue tumours. Joumal of Pathology 1989;159:341-4.
4. Mehregan AH. Shapiro L. Angiolymphoid hyperplasia with eosinophilia. Arch Dermatol 1971;103:50-7.

5. Bartralot R. Gracia Patos V. Hueto J. Angiolymphoid hyperplasia with eosinophilia affecting the oral mucosa. Br J Dermatol 1996:134:744-8.

6. Oslen TG, Helwing EB. Angiolymphoid hperplasia with eosinophilia. A clinico-pathologic study of 116 patients. J Am Acad Dermatol 1985;12:781-96.

7. Kennedy CTC. Angiolymphoid hyperplasia with eosinophilia In:Champion RH, Burton JL, Burns DA, Breathnach SM, editors. Rook/Wilkinson/Ebling Textbook of dermatology. $6^{\text {th }}$ ed, London, 1998; Blackwell Science Lid,3027-8. 